\title{
Heavy Metal Pollution Risk in Soil and Groundwater around a Copper Concentrator in Inner Mongolia
}

NENGZHAN ZHENG ${ }^{1}$, YANGUO TENG $^{2}$, WEIFENG YUE ${ }^{3}$, HONG LIU $^{3}$, JIE YANG ${ }^{3}$ AND YUANZHENG ZHAI ${ }^{3}$

${ }^{1}$ Beijing Normal University

${ }^{2}$ Engineering Research Center of Groundwater Pollution Control and Remediation, Ministry of Education, Beijing 100875

${ }^{3}$ College of Water Sciences, Beijing Normal University, Beijing 100875

Presenting Author: 1500010332@qq.com

The unreasonable exploitation of metal mines is one of the critical causes of heavy metal pollution in soil-groundwater of Inner Mongolia Autonomous Region. It not only reduces the quality of regional soil groundwater, but also seriously damages the regional agriculture and animal husbandry activities. In this study, 57 soil samples were collected from a copper mine flotation plant in Ulat Houqi, Bayannur city. The contents and spatial variation characteristics of $\mathrm{Cu}, \mathrm{As}, \mathrm{Cr}, \mathrm{Cd}, \mathrm{Pb}, \mathrm{Mn}$, and $\mathrm{Zn}$ in soil samples were analyzed. The element forms in soil samples were analyzed by BCR method. In addition, DO, TDS, $\mathrm{pH}$ and other indicators of regional groundwater samples and heavy metal concentrations were monitored through six monitoring wells. The results showed that the contents of the above heavy metals in the topsoil samples showed a significant downward trend with the increase of the distance between the sampling point and the slag heap, and also showed the characteristics of rapid decline with the growth of depth. The average and maximum concentrations of $\mathrm{Cu}$ in the regional soil were $338.04 \mathrm{mg} / \mathrm{kg}$ and $2356.84 \mathrm{mg} / \mathrm{kg}$, respectively, the pollution degree of $\mathrm{Cu}$ is very serious in the study area, $\mathrm{As}$ and $\mathrm{Cd}$ pollution exist in the topsoil, but other heavy metals do not reach the pollution levels. Furthermore, the risk of pollution in groundwater is controllable. This study can provide some support for heavy metal pollution control and risk prevention and control of soil and groundwater in mining area.

\section{Acknowledgments}

This study was supported by the Major Science and Technology Program of Inner Mongolia Autonomous Region (2019ZD00105). 